\title{
Design of Quad-Band Rat-Race Coupler for GSM/WiMAX/WLAN/Satellite Applications
}

\author{
Ayman A. ALTHUWAYB \\ Department of Electrical Engineering, Jouf University, Sakaka, Aljouf 72388, Kingdom of Saudi Arabia \\ aaalthuwayb@ju.edu.sa
}

Submitted October 3, 2020 / Accepted January 11, 2021

\begin{abstract}
In this communication, a novel quad-band ratrace coupler (RRC) is developed for GSM/WiMAX/WLAN/Satellite applications. A conventional RRC is converted to exhibit quad-band operation by using a quad-band microstrip-line (QBML). The proposed QBML is constructed by two coupledlines, one series transmission-line and two short-ended stubs. The ABCD matrix method is applied to develop the design formulas. Based on these formulas, a quad-band RRC operating at $1.8 \mathrm{GHz}, 3.5 \mathrm{GHz}, 5.4 \mathrm{GHz}$, and $7.1 \mathrm{GHz}$ is designed and verified through fabrication and measurement. The measurement and full-wave simulation responses are very much consistent as expected.
\end{abstract}

\section{Keywords}

Rat-race coupler, quad-band, coupled-line

\section{Introduction}

The rat-race coupler (RRC) is one of the essential and widely used components in advanced RF/Microwave system applications. Several techniques for the design of wideband RRCs have been reported [1-12]. These RRCs are suitable for single-band/broadband applications. Due to multistandard communication systems, multi-band RF/microwave front-end components are highly desirable, which leads to reduction in both cost as well as size of the overall system. In recent years, many techniques have been employed to design dual-band [13-23], triple-band [24-28] and quad-band [29-31] components. In [14], a triple-section branch-line coupler has been employed to design a dual-band RRC. In [15], a single-band RRC has been converted into a dual-band RRC with reconfigurable power division. In [16], a dualband RRC has been developed employing $\pi$-shaped topology based on glass-integrated passive device technology. In [17], the $\pi$-shaped stepped impedance topology has been applied for the design of a dual-band RCC. In [18], a dual-band RRC has been realized by applying two additional shuntstubs with the conventional single-band RRC. In [20], two dual-band RRC have been realized by employing T-shaped topology and an additional open-ended stub. In [21], a modified structure with an open-ended stub has been used to develop a dual-band RRC with arbitrary power division. It is observed that design of dual-band devices are explored extensively but multi-band components are highly desirable for advanced communication systems.

In the literature, several techniques have been employed for the development of triple-band [24-28] and quad-band [29-31] devices. In [24-25], triple-band impedance transformers have been realized. In [26], a triple-band RRC has been developed using resonators. In [27], metamaterial transmission-line has been used for the design of triple-band RRC. In [28], a T-shaped stepped impedance transformer has been applied to design a triple-band RRC. In [29], a H-shaped topology has been applied to realize a quad-band transformer for ultra-high transforming ratio. In [30], laterally offset dual-ring resonator and dual-ring split-resonators have been employed for the design of quad-band RRC woth spurious response. In [31], the concept of negative refractive-index transmission-line has been applied for the development of quad-band RRC. In literature, it is found that very few multiband RRC have been realized. Therefore, the design and validation of quad-band RRC needs to be explored further.

This paper presents a novel design procedure for development of quad-band rat-race coupler (RRC) for GSM/WiMAX/WLAN/Satellite applications. A quad-band microstrip-line (QBML) is employed in place of $\lambda / 4$ microstrip-lines of the traditional RRC. The closed-form formulas are derived by applying ABCD matrices. Finally, a prototype of quad-band RRC is validated through fabrication and experimentation. The key features of the proposed quad-band RRC are summarized as follows:

1. A new quad-band microstrip-line architecture is proposed and investigated.

2. Mathematical derivations are formed using ABCD matrx method, which provides the benefit of flexibility of the proposed quad-band microstrip-line.

3. A simple design approach is summarized for the development of quad-band RRC. 
4. A quad-band RRC is designed and verified through the fabrication and measurement for GSM/WiMAX/WLAN/Satellite applications.

5. The fabricated prototype exhibits quad-band operation, good isolation and low magnitude and phase imbalance.

\section{Mathematical Study of The Quad- Band Microstrip-Line}

The topology of the proposed quad-band microstripline (QBML) is depicted in Fig. 1. The QBML is configured as a $\Pi$-shaped topology inserted between the coupled lines. The П-shaped topology is composed of a series transmissionline $\left(Z_{\mathrm{L}}, 2 \theta_{\mathrm{K}}\right)$ and two shunt-ended stubs $\left(Z_{\mathrm{M}}, \theta_{\mathrm{K}}\right)$. The even/odd-mode characteristic impedances of the coupled-line $\left(\theta_{\mathrm{K}}\right)$ are $Z_{\mathrm{Ke}}$ and $Z_{\mathrm{Ko}}$, respectively. This QBML is equivalent to the conventional microstrip-line having characteristic impedance of $Z_{C}$ at four distinct frequency bands. The ABCD matrices of the proposed QBML and the conventional $\lambda / 4$ microstrip-line are computed by following [29]:

$$
\begin{aligned}
& {\left[\begin{array}{cc}
A_{\mathrm{T}} & B_{\mathrm{T}} \\
C_{\mathrm{T}} & D_{\mathrm{T}}
\end{array}\right]=M_{\mathrm{K}} M_{\mathrm{L}} M_{\mathrm{M}} M_{\mathrm{L}} M_{\mathrm{K}}= \pm M_{\mathrm{C}},} \\
& M_{\mathrm{K}}=\left[\begin{array}{cc}
\cos \theta_{\mathrm{K}} & \mathrm{j} \frac{\left(Z_{\mathrm{Ke}}+Z_{\mathrm{Ko}}\right) \sin \theta_{\mathrm{K}}}{2} \\
\mathrm{j} \frac{2 \sin \theta_{\mathrm{K}}}{Z_{\mathrm{Ke}}+Z_{\mathrm{Ko}}} & \cos \theta_{\mathrm{K}}
\end{array}\right], \\
& M_{\mathrm{L}}=\left[\begin{array}{cc}
1 & 0 \\
-\mathrm{j} \frac{\cot \theta_{\mathrm{K}}}{Z_{\mathrm{L}}} & 1
\end{array}\right], \\
& M_{\mathrm{M}}=\left[\begin{array}{cc}
\cos 2 \theta_{\mathrm{K}} & \mathrm{j} Z_{\mathrm{M}} \sin 2 \theta_{\mathrm{K}} \\
\mathrm{j} \frac{\sin 2 \theta_{\mathrm{K}}}{Z_{\mathrm{M}}} & \cos 2 \theta_{\mathrm{K}}
\end{array}\right], \\
& M_{\mathrm{C}}=\left[\begin{array}{cc}
0 & \mathrm{j} Z_{\mathrm{C}} \\
\frac{\mathrm{j}}{Z_{\mathrm{C}}} & 0
\end{array}\right] .
\end{aligned}
$$

Here, $M_{\mathrm{C}}$ and $Z_{\mathrm{C}}$ are the ABCD-matrix and characteristic impedance of a traditional $\lambda / 4$ microstrip-line. By setting $Z_{\mathrm{K}}=Z_{\mathrm{Ke}}+Z_{\mathrm{Ko}}$ and employing matrix-inverse properties, equation (1) can be expressed as:

$$
\begin{gathered}
M_{\mathrm{L}} M_{\mathrm{M}} M_{\mathrm{L}}= \pm M_{\mathrm{K}}^{-1} M_{\mathrm{C}} M_{\mathrm{K}}^{-1}, \\
{\left[\begin{array}{cc}
P+\frac{2 Z_{\mathrm{M}}}{Z_{\mathrm{L}}} R & \mathrm{j} Z_{\mathrm{M}} Q \\
\frac{\mathrm{j} Q}{Z_{\mathrm{M}}}-\frac{\mathrm{j} 2 P \cot \theta_{\mathrm{K}}}{Z_{\mathrm{L}}}-\frac{\mathrm{j} 2 R Z_{\mathrm{M}}}{Z_{\mathrm{M}}^{2} \sin \theta_{\mathrm{K}}} & P+\frac{2 Z_{\mathrm{M}}}{Z_{\mathrm{L}}} R
\end{array}\right]} \\
= \pm\left[\begin{array}{cc}
\left.\frac{Z_{\mathrm{K}}}{4 Z_{\mathrm{C}}}+\frac{Z_{\mathrm{C}}}{Z_{\mathrm{K}}}\right) Q & \mathrm{j} Z_{\mathrm{C}} R-\mathrm{j} \frac{Z_{\mathrm{K}}^{2}}{4 Z_{\mathrm{C}}} S \\
\frac{\mathrm{j} R}{Z_{\mathrm{C}}}-\mathrm{j} \frac{Z_{\mathrm{C}}}{4 Z_{\mathrm{K}}^{2}} S & \left(\frac{Z_{\mathrm{K}}}{4 Z_{\mathrm{C}}}+\frac{Z_{\mathrm{C}}}{Z_{\mathrm{K}}}\right) Q
\end{array}\right],
\end{gathered}
$$

where: $P=\cos 2 \theta_{\mathrm{K}}, Q=\sin 2 \theta_{\mathrm{K}}, R=\cos ^{2} \theta_{\mathrm{K}}$ and $S=\sin ^{2} \theta_{\mathrm{K}}$.

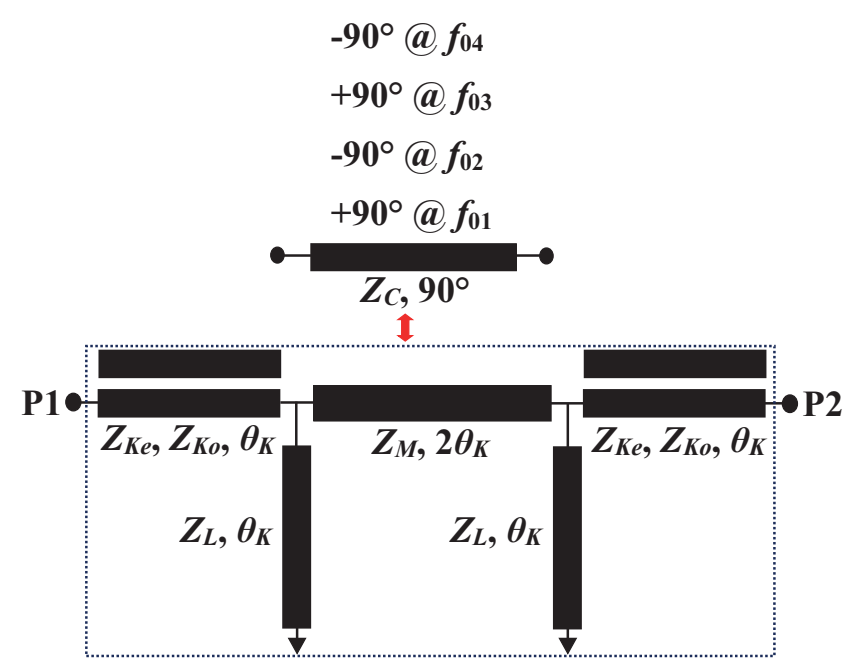

Fig. 1. Schematic of the proposed quad-band microstrip-line (QBML).

Applying $\mathrm{ABCD}$ matrix properties, equation (7) can be solved as:

$$
\begin{array}{r}
P+\frac{2 Z_{\mathrm{M}}}{Z_{\mathrm{L}}} R= \pm\left(\frac{Z_{\mathrm{K}}}{4 Z_{\mathrm{C}}}+\frac{Z_{\mathrm{C}}}{Z_{\mathrm{K}}}\right) Q, \\
\mathrm{j} Z_{\mathrm{M}} Q= \pm\left[\mathrm{j} Z_{\mathrm{C}} R-\mathrm{j} \frac{Z_{\mathrm{K}}^{2}}{2 Z_{\mathrm{C}}} S\right], \\
P+\frac{2 Z_{\mathrm{M}}}{Z_{\mathrm{L}}} R= \pm\left(\frac{Z_{\mathrm{K}}}{4 Z_{\mathrm{C}}}+\frac{Z_{\mathrm{C}}}{Z_{\mathrm{K}}}\right) Q .
\end{array}
$$

Simplifying equation (8), we obtain:

$$
\begin{array}{r}
\tan ^{2} \theta_{\mathrm{K}} \pm\left(\frac{Z_{\mathrm{K}}^{2}+4 Z_{\mathrm{C}}^{2}}{2 Z_{\mathrm{K}} Z_{\mathrm{C}}}\right) \tan \theta_{\mathrm{K}}-\left(1+\frac{2 Z_{\mathrm{M}}}{Z_{\mathrm{L}}}\right)=0, \\
\tan ^{2} \theta_{\mathrm{K}} \pm\left(\frac{8 Z_{\mathrm{M}} Z_{\mathrm{C}}}{2 Z_{\mathrm{K}}^{2}}\right) \tan \theta_{\mathrm{K}}-\frac{4 Z_{\mathrm{C}}^{2}}{Z_{\mathrm{K}}^{2}}=0, \\
\tan ^{2} \theta_{\mathrm{K}} \pm\left(\frac{Z_{\mathrm{K}}^{2}+4 Z_{\mathrm{C}}^{2}}{2 Z_{\mathrm{K}} Z_{\mathrm{C}}}\right) \tan \theta_{\mathrm{K}}-\left(1+\frac{2 Z_{\mathrm{M}}}{Z_{\mathrm{L}}}\right)=0 .
\end{array}
$$

The values of $\tan \theta_{\mathrm{K}}$ in equation (9) are expressed as:

$$
\tan \theta_{\mathrm{K}}= \pm\left[\frac{2 Z_{\mathrm{C}}}{Z_{\mathrm{K}}}\left(\sqrt{1+\frac{\left(Z_{\mathrm{K}}^{2}+4 Z_{\mathrm{C}}^{2}\right)^{2}}{64 Z_{\mathrm{C}}^{2}}}-\frac{Z_{\mathrm{K}}^{2}+4 Z_{\mathrm{C}}^{2}}{8 Z_{\mathrm{C}}^{2}}\right)\right]
$$

In order to obtain quad-band operation, the proposed QBML and conventional TL must be equivalent at four different frequencies of $f_{01}, f_{02}, f_{03}$ and $f_{04}$. It is considered that $f_{01}<f_{02}<f_{03}<f_{04}$. Let the electrical lengths of the 
microstrip-lines are $\theta_{K 1}, \theta_{K 2}, \theta_{K 3}$ and $\theta_{K 4}$ at the center frequencies of $f_{01}, f_{02}, f_{03}$ and $f_{04}$, respectively.

Hence, the four solutions of $\tan \theta_{\mathrm{K}}$ are determined as:

$$
\begin{gathered}
\theta_{K 1}=\tan ^{-1}\left[\frac { 2 Z _ { \mathrm { C } } } { Z _ { \mathrm { K } } } \left(\sqrt{\left.\left.1+\frac{\left(Z_{\mathrm{K}}^{2}+4 Z_{\mathrm{C}}^{2}\right)^{2}}{64 Z_{\mathrm{C}}^{4}}-\frac{Z_{\mathrm{K}}^{2}+4 Z_{\mathrm{C}}^{2}}{8 Z_{\mathrm{C}}^{2}}\right)\right],}\right.\right. \\
\theta_{K 2}=\tan ^{-1}\left[\frac { 2 Z _ { \mathrm { C } } } { Z _ { \mathrm { K } } } \left(\sqrt{\left.\left.1+\frac{\left(Z_{\mathrm{K}}^{2}+4 Z_{\mathrm{C}}^{2}\right)^{2}}{64 Z_{\mathrm{C}}^{4}}+\frac{Z_{\mathrm{K}}^{2}+4 Z_{\mathrm{C}}^{2}}{8 Z_{\mathrm{C}}^{2}}\right)\right],}\right.\right. \\
\theta_{K 3}=\pi-\theta_{K 2}, \\
\theta_{K 4}=\pi-\theta_{K 1} .
\end{gathered}
$$

Employing the (11a)-(11d), we determine:

$$
\begin{array}{r}
f_{02}=f_{01} \frac{\theta_{K 2}}{\theta_{K 1}}, \\
f_{03}=f_{02}\left[\frac{\pi}{\theta_{K 2}}-1\right], \\
f_{04}=f_{01}\left[\frac{\pi}{\theta_{K 1}}-1\right] .
\end{array}
$$

The impedances $\left(Z_{M}\right.$ and $\left.Z_{L}\right)$ are determined by solving (9):

$$
\begin{aligned}
& Z_{\mathrm{M}}=Z_{\mathrm{K}}\left(\frac{Z_{\mathrm{K}}^{2}+4 Z_{\mathrm{C}}^{2}}{16 Z_{\mathrm{C}}^{2}}\right), \\
& Z_{\mathrm{L}}=\frac{Z_{\mathrm{K}}^{3}}{8 Z_{\mathrm{C}}^{2}}\left(\frac{Z_{\mathrm{K}}^{2}+4 Z_{\mathrm{C}}^{2}}{4 Z_{\mathrm{C}}^{2}-Z_{\mathrm{K}}^{2}}\right) .
\end{aligned}
$$

The procedure for designing of quad-band RRC can be summarized as follows:

1. First, the impedance values of $3 \mathrm{~dB}$ traditional RRC are chosen as $Z_{\mathrm{A}}=70 \Omega$ and $Z_{\mathrm{B}}=70 \Omega$. Select, $Z_{\mathrm{C}}=Z_{\mathrm{A}}=Z_{\mathrm{B}}$.

2. The electrical length $\theta_{\mathrm{K}}=\theta_{K 1}$ can be determine from (11a).

3. The first operating frequency $f_{01}$ is assumed, for a particular value of $Z_{\mathrm{K}}$ (76.5 to $111.5 \Omega$ ), other operating frequencies $f_{02}, f_{03}$, and $f_{04}$ can be determined employing (12a), (12b), and (12c), respectively.

4. Applying (13) and (14), determine the values of $Z_{M}$ and $Z_{\mathrm{L}}$, if these parameters are exceeding the fabrication limit of microstrip technology, return to step-3 and choose a suitable value of $Z_{\mathrm{K}}$.
5. Determine the dimensions of the proposed quad-band $\mathrm{RRC}$ at the first mid-band frequency $\left(f_{01}\right)$.

Based on the above sythesis approach, the design parametrs $\left(Z_{\mathrm{M}}, Z_{\mathrm{L}}, f_{02}, f_{03}, f_{04}\right.$ and $\left.\theta_{\mathrm{K}}\right)$ are computed by using the equations (8)-(13). Based on the derived closedform formulas, we have eight unknowns $\left(Z_{\mathrm{K}}, Z_{\mathrm{M}}, Z_{\mathrm{L}}, f_{01}\right.$, $f_{02}, f_{03}, f_{04}$ and $\left.\theta_{\mathrm{K}}\right)$ and six equations to obtain solutions. Hence, two degrees of freedom are exist. Therefore, the parameters $Z_{\mathrm{K}}$ and $f_{01}$ are chosen as free variables. Considering the fabrication limit of $Z_{\mathrm{M}}$ and $Z_{\mathrm{L}}(20 \Omega \leq 150 \Omega), Z_{\mathrm{K}}$ can be chosen between $76.5 \Omega$ to $111.5 \Omega$. The operating frequencies $\left(f_{02}, f_{03}\right.$ and $\left.f_{04}\right)$ can be tuned by varying any one of the free variable (either $Z_{\mathrm{K}}$ or $f_{01}$ ). For example, Table 1 shows the different values of $f_{02}, f_{03}, f_{04}$ at various $f_{01}$ and for a fixed $Z_{\mathrm{K}}=95 \Omega$. Similarly, Table 2 depicts the variation of $f_{02}, f_{03}, f_{04}$ for various $Z_{\mathrm{K}}$ and at fixed $f_{01}=1.8 \mathrm{GHz}$. Hence, the operating frequencies $f_{02}, f_{03}, f_{04}$ can be tuned by varying the free variables.

\begin{tabular}{cccc}
\hline $\mathbf{f}_{\mathbf{0 1}}(\mathrm{GHz})$ & $\mathbf{f}_{\mathbf{0 2}}(\mathrm{GHz})$ & $\mathbf{f}_{\mathbf{0 3}}(\mathrm{GHz})$ & $\mathbf{f}_{\mathbf{0 4}}(\mathrm{GHz})$ \\
\hline 0.7 & 1.34 & 2.0 & 2.7 \\
\hline 0.9 & 1.72 & 2.63 & 3.45 \\
\hline 1.2 & 2.3 & 3.51 & 4.6 \\
\hline 1.5 & 2.86 & 4.4 & 5.75 \\
\hline 1.8 & 3.44 & 5.27 & 6.91 \\
\hline
\end{tabular}

Tab. 1. The values of $f_{02}, f_{03}, f_{04}$ at various $f_{01}$ and for a fixed $Z_{\mathrm{K}}=95 \Omega$.

\begin{tabular}{cccc}
\hline $\mathbf{Z}_{\mathrm{K}}(\boldsymbol{\Omega})$ & $\mathbf{f}_{\mathbf{0 2}}(\mathrm{GHz})$ & $\mathbf{f}_{\mathbf{0 3}}(\mathrm{GHz})$ & $\mathbf{f}_{\mathbf{0 4}}(\mathrm{GHz})$ \\
\hline 80 & 3.0 & 4.41 & 5.63 \\
\hline 85 & 3.15 & 4.68 & 6.0 \\
\hline 90 & 3.29 & 4.97 & 6.46 \\
\hline 95 & 3.44 & 5.27 & 6.91 \\
\hline 100 & 3.6 & 5.58 & 7.38 \\
\hline
\end{tabular}

Tab. 2. The values of $f_{02}, f_{03}, f_{04}$ for various $Z_{\mathrm{K}}$ and at fixed $f_{01}=1.8 \mathrm{GHz}$.

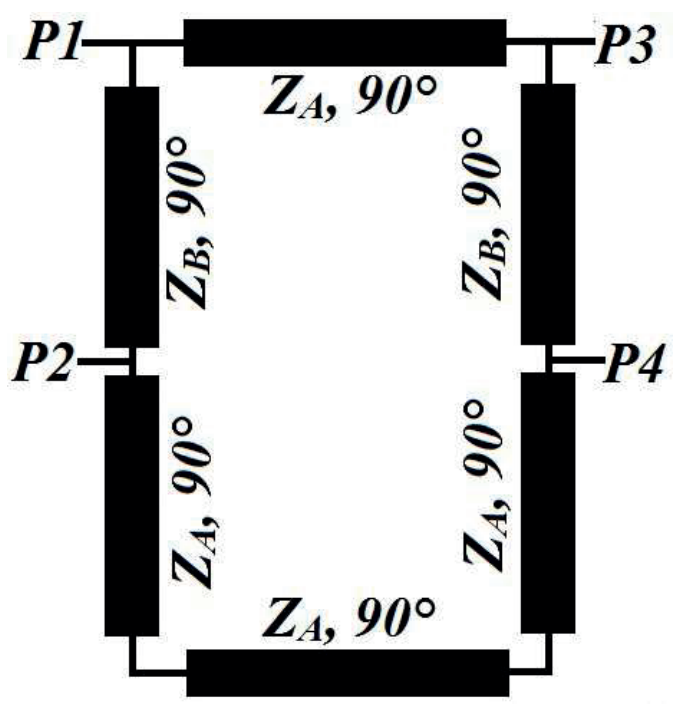

Fig. 2. Schematics of the conventional rat-race coupler. 


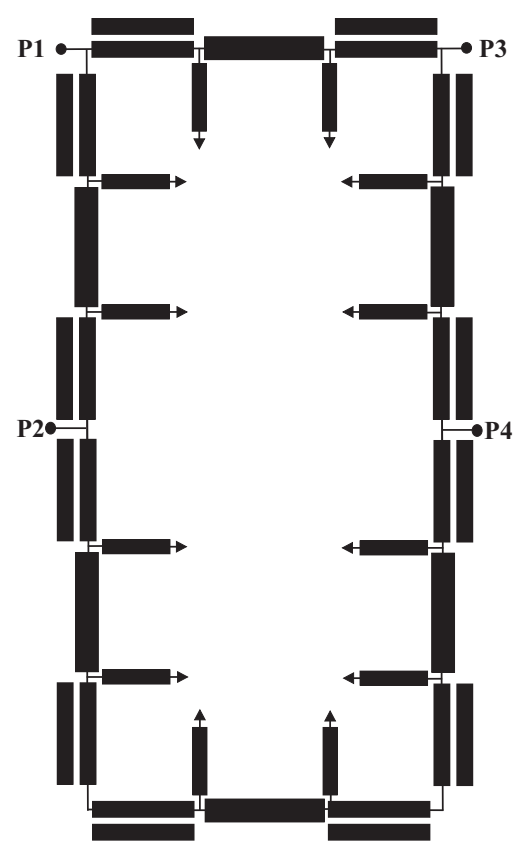

Fig. 3. Schematics of the proposed quad-band rat-race coupler.

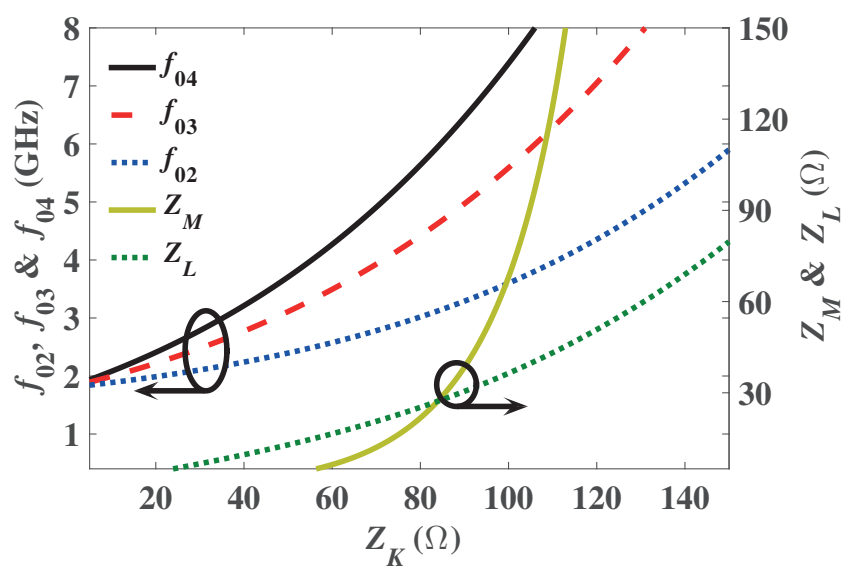

Fig. 4. Design curve for the proposed quad-band RRC.

\section{Fabrication and Validation}

The geometrical layout of the conventional 3-dB ratrace coupler (RRC) is depicted in Fig. 2. The characteristic impedances of the $\lambda / 4$ microstrip-lines of the RRC are given as $Z_{\mathrm{A}}=Z_{\mathrm{B}}=70.7 \Omega$. These microstrip-lines are replaced by the proposed QBML to develop a quad-band RRC as illustrated in Fig. 3. Considering $Z_{\mathrm{C}}=Z_{\mathrm{A}}=Z_{\mathrm{B}}=70.7 \Omega$, a design curve is plotted for the calculation of operating frequencies and impdances of the proposed QBML as illustrated in Fig. 4. Based on the above design procedure, the circuit parameters for a $70.7 \Omega$ microstrip-line are computed as $Z_{\mathrm{Ke}}=59.7 \Omega$, $Z_{\mathrm{Ko}}=37.3 \Omega, Z_{\mathrm{M}}=35.6 \Omega, Z_{\mathrm{L}}=63.4 \Omega$ and $\theta_{\mathrm{K}}=36.4^{\circ}$. Using these parameters, the physical dimensions are computed at $f_{01}$. To verify the concept, a quad-band $3-\mathrm{dB} \mathrm{RRC}$ is fabricated for GSM/WiMAX/WLAN/Satellite applications operating at $1.8,3.5,5.4$, and $7.1 \mathrm{GHz}$, respectively.

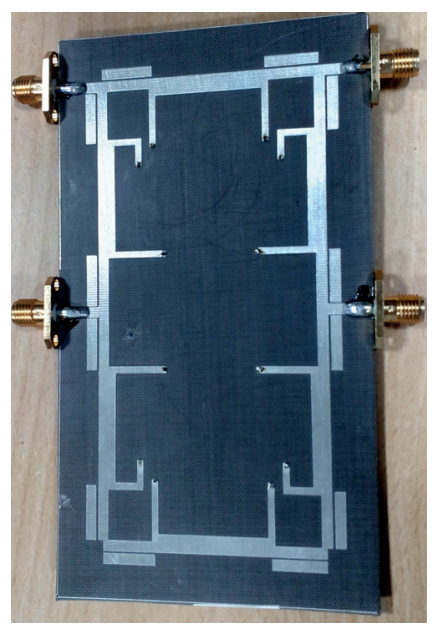

Fig. 5. Fabricated prototype of the proposed quad-band rat-race coupler.

A Rogers RT/Duriod 5870 substrate $\left(\epsilon_{\mathrm{r}}=2.33\right.$, thickness $=0.787 \mathrm{~mm}, \tan \delta=0.0009)$ is employed for fabrication. The fabricated prototype of the proposed quad-band RRC is illustrated in Fig. 5. The circuit size of the quadfrequency RRC is $0.40 \lambda_{\mathrm{g}} \times 0.80 \lambda_{\mathrm{g}} \mathrm{mm}^{2}$, here $\lambda_{\mathrm{g}}$ is the guided wavelength at $f_{01}$.

The Circuit, full-wave simulated and tested magnitude responses are depicted in Fig. 6 and Fig. 7. The return loss $\left(\left|S_{11}\right|\right)$ and isolation $\left(\left|S_{41}\right|\right)$ are greater than $20 \mathrm{~dB}$ and $27 \mathrm{~dB}$, respectively. From measured results, the magnitude at transmission $\left(\left|S_{21}\right|\right)$ and coupling $\left(\left|S_{31}\right|\right)$ ports are found as $\pm 0.5 \mathrm{~dB}$ deviation from the ideal value of $3 \mathrm{~dB}$. Fig. 8 and Fig. 9 depict the in-phase and out-phase responses of the proposed quad-band $\mathrm{RRC}$, respectively. Considering the magnitude imbalance of $\Delta \mathrm{M}\left(\left|S_{21}\right|-\left|S_{31}\right|\right)=0.5 \mathrm{~dB}$ and phase imbalance of $\triangle \Phi\left(\angle S_{21}-\angle S_{31}\right)=5^{\circ}$, the bandwidth is greater than $200 \mathrm{MHz}$ at all the operating frequency. The experimental performances of the fabricated quad-band RRC are summarized in Tab. 3.

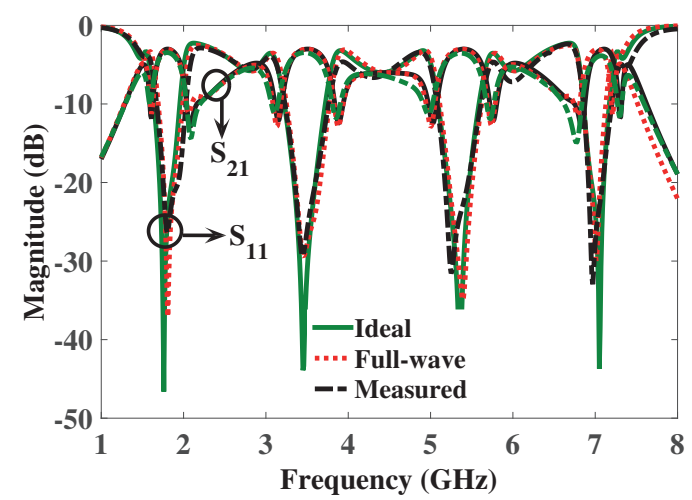

Fig. 6. Simulated and measured $S$-parameters response $\left(S_{11}\right.$ and $\left.S_{21}\right)$. 


\begin{tabular}{ccccccc}
\hline Ref. & Techniques & Operation & RL $(\mathrm{dB})$ & ISL $(\mathrm{dB})$ & MI $(\mathrm{dB})$ & Size $\left(\lambda_{\mathbf{g}}^{2}\right)$ \\
\hline$[26]$ & $\pi$-shaped resonator & Tri-band & $<-10$ & $<-22$ & $\leq 1.4$ & NR \\
\hline$[27]$ & MTM TL & Tri-band & $<-10$ & $<-20$ & $\leq 2.0$ & 0.063 \\
\hline$[28]$ & T-shaped stepped impedance & Tri-band & $<-20$ & $<-20$ & $\leq 0.6$ & 0.26 \\
\hline$[30]$ & LODR+CDSR slots & Quad-band & $<-15$ & $<-29$ & $\leq 3.3$ & 0.27 \\
\hline$[31]$ & GNRI-TL unit & Quad-band & $<-10$ & $<-10$ & $\leq 3.4$ & 0.02 \\
\hline This Work & Coupled-line, transmission-line \& shunt-stub & Quad-band & $<-\mathbf{2 0}$ & $<-\mathbf{2 7}$ & $\leq \mathbf{0 . 9}$ & $\mathbf{0 . 3 2}$ \\
\hline
\end{tabular}

Tab. 3. Comparative analysis of the proposed and existing multi-band RRC. (RL: Return Loss; ISL: Isolation; MI: Magnitude Imbalance; PI: Phase Imbalance; NR: Not Reported).

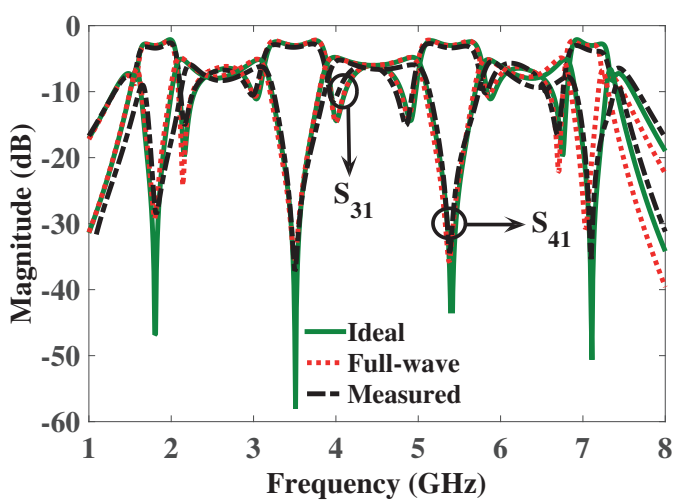

Fig. 7. Simulated and measured S-parameters response ( $S_{31}$ and $\left.S_{41}\right)$.

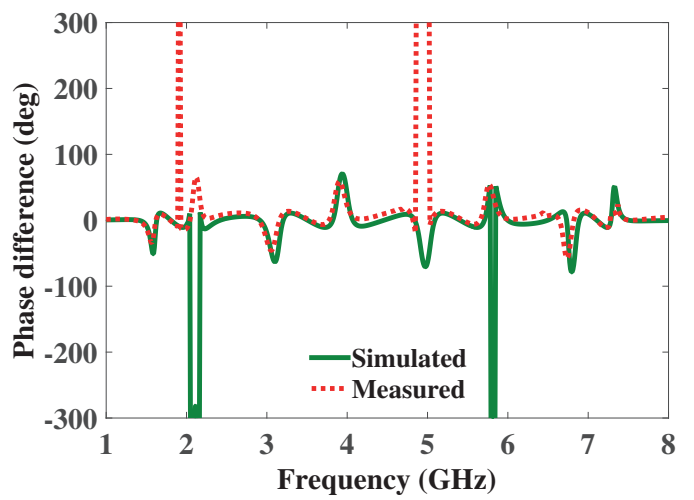

Fig. 8. Simulated and measured in-phase response $\angle S_{21}-\angle S_{31}$.

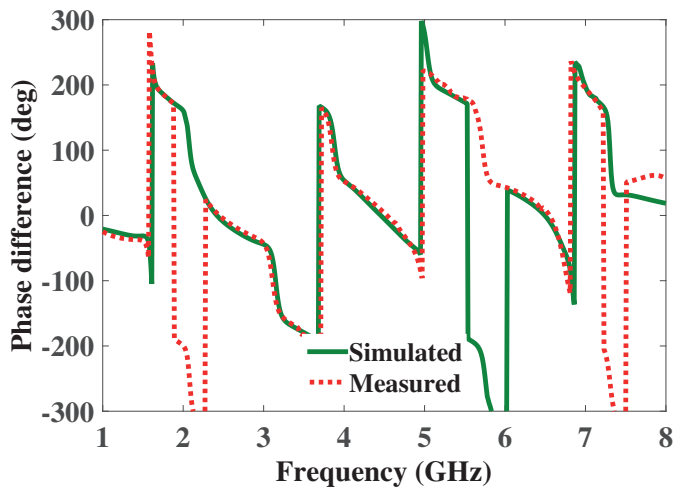

Fig. 9. Simulated and measured out-phase response $\angle S_{24}-$ $\angle S_{34}$.

\begin{tabular}{ccccc}
\hline Freq. $(\mathrm{GHz})$ & $\mathbf{1 . 8}$ & $\mathbf{3 . 6}$ & $\mathbf{5 . 4}$ & $\mathbf{7 . 1}$ \\
\hline$\left|S_{11}\right|(\mathrm{dB})$ & -26.3 & -26 & -22.6 & -19.1 \\
\hline$\left|S_{21}\right|(\mathrm{dB})$ & -3.46 & -3.49 & -3.56 & -3.91 \\
\hline$\left|S_{31}\right|(\mathrm{dB})$ & -3.4 & -3.28 & -3.47 & -3.79 \\
\hline$\left|S_{41}\right|(\mathrm{dB})$ & -27.34 & -37.13 & -32.58 & -35.38 \\
\hline In-phase $(\mathrm{deg})$ & 0.6 & 2.4 & 3.1 & 1.06 \\
\hline Out-phase $(\mathrm{deg})$ & 180 & 182.5 & 181.7 & 180.1 \\
\hline
\end{tabular}

Tab. 4. Experimental performance of the quad-band RRC.

Table 4 depicts the comparative analysis of the proposed and existing multi-band RRC. The proposed quad-band RRC exhibits greater return loss, isolation and magnitude imbalance when compared to [26-31]. The size of the proposed quad-band RRC is larger than the existing multi-band RRC but provides a simple mathematical analysis to achieve quadband operation.

\section{Conclusion}

In this article, design of a novel quadband rat-race coupler (RRC) has been reported for GSM/WiMAX/WLAN/Satellite applications. The conventional RRC has been converted to provide quad-band characteristics by employing a novel quad-band microstripline (QBML). The proposed QBML has been configured by using two coupled-lines, one series microstrip-line and two short-ended stubs. The design formulas are derived by applying ABCD matrix method. Based on these formulas, a quad-band rat-race coupled has been designed and verified through fabrication and experimentation. The full-wave simulation and experimentation results show good agreement as expected.

\section{References}

[1] KAWAI, T., OHTA, I., ENOKIHARA A. Design methods for broadband $3 \mathrm{~dB}$ branch-line and rat-race hybrids. IEICE Electronics Express, 2013, vol. 10, no. 12, p. 1-14, DOI: 10.1587/elex.10.20132004

[2] WANG, S., HUANG, B., LI, Z. A miniaturized 10/24-GHz ratrace coupler using synthetic transmission lines on glass substrate. IEICE Electronics Express, 2011, vol. 10, no. 17, p. 1425-1430. DOI: $10.1587 /$ elex.8.1425

[3] SONG, W., DEGUCHI, H., TSUJI, M. A harmonic suppression and size-reduced rat-race hybrid coupler using dual coupled-lines. IEICE Electronics Express, 2012, vol. 9, no. 13, p. 1083-1089. DOI: $10.1587 /$ elex.8.1425 
[4] TSENG, C. H., CHANG, C. L. A rigorous design methodology for compact planar branch-line and rat-race couplers with asymmetrical T-structures. IEICE Electronics Express, 2012, vol. 60, no. 7, p. 2085-2091. DOI: 10.1109/TMTT.2012.2195019

[5] CHANG, W. S., LIANG, C. H., CHANG, C. Y. Wideband high-isolation and perfect-balance microstrip rat-race coupler. $I E$ ICE Electronics Express, 2012, vol. 48, no. 7, p. 382-383. DOI: $10.1049 / \mathrm{el} .2012 .0227$

[6] TSENG, C. H., CHEN, H. J. Compact rat-race coupler using shunt-stub-based artificial transmission lines. IEEE Microwave and Wireless Components Letters, 2008, vol. 18, no. 11, p. 734-736. DOI: 10.1109/LMWC.2008.2005225

[7] WU, L. S., MAO, J., YIN, W. Y. Miniaturization of rat-race coupler with dual-band arbitrary power divisions based on stepped-impedance double-sided parallel-strip line. IEEE Transactions on Components, Packaging and Manufacturing Technology, 2012, vol. 2, no. 12, p. 2017-2030. DOI: 10.1109/TCPMT.2012.2211597

[8] TOLIN, E., BAHR, A. Miniaturized and reconfigurable rat-race coupler based on artificial transmission lines. IEEE Microwave and Wireless Components Letters, 2020, vol. 30, no. 4, p. 375-377. DOI: 10.1109/LMWC.2020.2972738

[9] KOU, J. T., WU, J. S., CHIOU, Y. C. Miniaturized rat race coupler with suppression of spurious passband. IEEE Microwave and Wireless Components Letters, 2007, vol. 17, no. 1, p. 46-48. DOI: 10.1109/LMWC.2006.887254

[10] TAN, X., LIN, F. A novel rat-race coupler with widely tunable frequency. IEEE Microwave and Wireless Components Letters, 2019, vol. 67, no. 3, p. 957-967. DOI: 10.1109/TMTT.2018.2889453

[11] FENG, W., CHE, W. SHI, C., et al. Balanced rat-race couplers with wideband common-mode suppression. IEEE Transactions on Microwave Theory and Techniques, 2019, vol. 67, no. 12, p. 4724-4732. DOI: 10.1109/TMTT.2019.2946158

[12] LIN, F., MA, H. Design of a class of filtering couplers with reconfigurable frequency. IEEE Transactions on Microwave The ory and Techniques, 2018, vol. 66, no. 9, p. 4017-4028. DOI: 10.1109/TMTT.2018.2842755

[13] BARIK, R. K., SIDDIQUI, R., KUMAR, K. V. P., et al. Design of a novel dual-band low noise amplifier incorporating dualband impedance transformer. 2016 International Conference on Signal Processing and Communications (SPCOM), 2016, p. 1-5. DOI: $10.1109 /$ SPCOM.2016.7746652

[14] CHENG, K. M. M., WONG, F. L. Dual-band rat-race coupler design using tri-section branch-line. Electronics Letters, 2007, vol. 43, no. 6, p. 41-42. DOI: 10.1049/el:20070018

[15] CAI, L. P., CHENG, K. M. M. A novel design of dual-band rat-race coupler with reconfigurable power-dividing ratio. IEEE Microwave and Wireless Components Letters, 2018, vol. 28, no. 1, p. 16-18. DOI: 10.1109/LMWC.2017.2779807

[16] TSENG, C. H., MOU, C. H., LIN, C. C., et al. Design of microwave dual-band rat-race couplers in printed-circuit board and GIPD technologies. IEEE Transactions on Components, Packaging and Manufacturing Technology, 2016, vol. 6, no. 2, p. 262-271. DOI: 10.1109/TCPMT.2015.2507371

[17] CHIN, K. S., LIN, K. M., WEI, Y. H., et al. Compact dual-band branch-line and rat-race couplers with stepped-impedance-stub lines. IEEE Transactions on Microwave Theory and Techniques, 2010, vol. 58, no. 5, p. 1213-1221. DOI: 10.1109/TMTT.2010.2046064

[18] CHENG, K. K. M., WONG, F. L. A novel rat race coupler design for dual-band applications. IEEE Microwave and Wireless Components Letters, 2005, vol. 15, no. 8, p. 521-523. DOI: 10.1109/LMWC.2005.852792
[19] KRISHNA, I. S., BARIK, R. K., KARTHIKEYAN, S. S. A dual-band crossover using cross-shaped microstrip line for small and large band ratios. International Journal of Microwave and Wireless Technologies, 2017, vol. 9, no. 8, p. 1629-1635. DOI: $10.1017 / S 1759078717000290$

[20] ZHANG, H., CHEN, K. J. Design of dual-band rat-race couplers. IET Microwaves Antennas \& Propagation, 2009, vol. 3, no. 3, p. 514-521. DOI: 10.1049/iet-map.2008.0019

[21] HE, Q., SHEN, J., LIU, Q., et al. A simplified dual-band rat-race hybrid for arbitrary power division ratio with only single shunt stub. Journal of Electromagnetic Waves and Applications, 2013, vol. 27, no. 16, p. 2101-2109. DOI: 10.1080/09205071.2013.832396

[22] BARIK, R. K., KARTHIKEYAN, S. S. Dual-frequency impedance transformer using coupled-line for ultra-high transforming ratio. Radioengineering, 2017, vol. 26, no. 4, p. 1067-1074. DOI: $10.13164 /$ re. 2017.1067

[23] BARIK, R. K., KUMAR, K. V. P., KARTHIKEYAN, S. S. Design of a dualband microstrip branchline balun using T-shaped coupled lines. Microwave Optical Technology Letters, 2017, vol. 59, no. 5, p. 1197-1202. DOI: $10.1002 /$ mop.30502

[24] BARIK, R. K., CHENG, Q. S., KARTHIKEYAN, S. S. An automatic design approach for microstrip line impedance transformer for triple-band application. In 2019 IEEE Asia-Pacific Microwave Conference (APMC). Singapore, 2019, p. 207-209. DOI: 10.1109/APMC46564.2019.9038330

[25] BARIK, R. K., KARTHIKEYAN, S. S. Design of dual/tri-frequency impedance transformer with ultra-high transforming ratio. International Journal of Microwave and Wireless Technologies, 2017, vol. 9 , no. 10, p. 1951-1960. DOI: 10.1017/S1759078717000952

[26] WANG, Z., JANG, J. S., PARK, C. W. Tri-band rat-race coupler using resonators. In IEEE International Conference on Microwave Technology \& Computational Electromagnetics. Beijing (China), 2011, p. 186-189. DOI: 10.1109/ICMTCE.2011.5915197

[27] CHENG, W. G., MING, W., GNAG, L., et al. Compact tri-band rat-race coupler based on novel metamaterial transmission line. In Asia-Pacific Microwave Conference (APMC). Nanjing (China), 2015, p. 1-3. DOI: 10.1109/APMC.2015.7411702

[28] CHU, Q. X., LIN F. A novel tri-band rat race coupler with T?shape step impedance transformers. Microwave and Optical Technology Letters, 2010, vol. 52, no. 6, p. 1240-1244. DOI: 10.1002/mop.25186

[29] BARIK, R. K., KARTHIKEYAN, S. S. A novel quad-band impedance transformer with ultra-high transforming ratio. AEU - International Journal of Electronics and Communications, 2017, vol. 78, p. 157-161. DOI: 10.1016/j.aeue.2017.05.030

[30] VELAN, S., KINGSLY, S. KANGASABAI, M., et al. Quad-band rat-race coupler with suppression of spurious pass-bands. IEEE Microwave and Wireless Components Letters, 2016, vol. 26, no. 7, p. 490-492. DOI: 10.1109/LMWC.2016.2575017

[31] PAPANAStasiou, A. C., GEORGHiOU, E. G, ElEFTHERIADES, G V. A quad-band rat-race coupler based on the generalized negative refractive-index transmission-line concept. In European Microwave Conference. Nuremberg (Germany), 2013, p. 302-305. DOI: 10.23919/EuMC.2013.6686651

\section{About the Authors ...}

Ayman Abdulhadi ALTHUWAYB received the B.Sc. de- 
gree (Hons.) in Electrical Engineering (Electronics and Communications) from Jouf University, Saudi Arabia, in 2011, the M.Sc. degree in Electrical Engineering from California State University, Fullerton, CA, USA, in 2015, and the Ph.D. degree in Electrical Engineering from Southern Methodist University, Dallas, TX, USA, in 2018. He is currently an Assistant Professor with the Department of Electrical Engineering at Jouf University, Kingdom of Saudi Arabia. His current research interests include antenna design and propagation, microwaves and millimeter-waves, wireless power transfer, ultrawideband and multiband antennas, filters and other. 